\title{
El papel de la mentoría en la construcción de la imagen profesional
}

\section{The role of mentoring in the professional image construction}

\author{
Mitzi Danae Morales Montes*
}

Esta investigación analiza la influencia de la mentoría informal en la construcción de la imagen profesional de los novatos de la carrera de Derecho. Los mentores suelen ser modelos de imagen profesional para sus aprendices, ya que les enseñan a proyectar eficiencia técnica y coherencia sociocultural en su trabajo cotidiano. Ambos componentes son valiosos en organizaciones institucionalizadas, como las de tipo jurídico, que valoran que los novatos, además de su conocimiento especializado, muestren un comportamiento y una vestimenta adecuados a la cultura organizacional. El estudio utiliza una perspectiva cualitativa para analizar los datos obtenidos de entrevistas en profundidad con egresados de Derecho de instituciones de educación superior pública y privada mexiquenses. Los resultados muestran que la vestimenta es una señal poderosa de competencia profesional, aunque su valor depende de distintos elementos.

This research analyses the informal mentoring influence in the professional image construction of recent law graduates. Mentors are usually professional image models for their apprentices, for they teach them to project technical efficiency and sociocultural consistency in their daily performance. Both characteristics are valuable in institutionalized organizations, such as those dealing with legal matters, where not only specialized knowledge is expected from new graduates, but also satisfactory and suitable behavior as well as a certain appropriate dress code for this kind of organizational culture. A qualitative perspective was used to analyze the data obtained through interviews with law graduates from private and public institutions in México State. The results show that clothing is a powerful sign of professional competence, although its value depends on different elements.

\author{
Palabras clave: \\ mentoría, \\ imagen \\ profesional, \\ profesión jurídica, \\ habilidades \\ sociales, \\ vestimenta laboral
}

\section{Keywords:}

mentoring, professional image, legal profession, social skills, work dress

Recibido: 17 de febrero de 2020 | Aceptado para su publicación: 30 de septiembre de 2020 | Publicado: 12 de noviembre de 2020

Recuperado de: https://sinectica.iteso.mx/index.php/SINECTICA/article/view/1101 doi: $10.31391 /$ S2007-7033(2020)0055-013

\footnotetext{
* Doctora en Ciencias, especialidad de Investigaciones Educativas, por el Cinvestav-IPN. Profesora-investigadora de la Universidad Autónoma Metropolitana, unidad Lerma. Líneas de investigación: educación superior privada, egresados universitarios, análisis organizacional. Correo electrónico: mdanaemm@gmail.com/https://orcid.org/0000-0001-5726-9682
} 


\section{INTRODUCCIÓN}

sta investigación analiza algunos aprendizajes que los profesionistas novatos 4 del derecho desarrollan gracias a la mentoría informal en los entornos laborales jurídicos. A través del proceso de formación de la imagen profesional de los novatos, estos construyen sus nociones de profesionalismo, en gran parte, basadas en las atribuciones que reciben de sus mentores y otros colegas expertos sobre su desempeño. En específico, en este trabajo abordamos la manera en que los profesionales aprenden a enviar señales adecuadas para construir su imagen profesional, en especial, aquellas referidas a la vestimenta laboral, las cuales contribuyen a ganar credibilidad en su capacidad para realizar un trabajo.

La mentoría brinda beneficios de diverso tipo (Ramaswami, Dreher, Bretz \& Wiethoff, 2010; Kay, Hagan \& Parker, 2009; Ehrich, Hansford \& Tennent, 2004; Van Emmerik, 2004; Swap, Leonard, Shields \& Abrams, 2001). Durante la socialización profesional con un mentor informal, el mentorado desarrolla los conocimientos técnicos y las habilidades especializadas que demanda el ejercicio de la profesión, así como saberes socioculturales, axiológicos, actitudinales o normas de la cultura organizacional. De manera paralela, se reconoce el apoyo emocional que suele brindar el experto y sus efectos favorables para el desempeño laboral. A pesar de estos beneficios, el aprendizaje del mentorado sobre la presentación personal y la vestimenta como componentes de la imagen profesional ha sido poco explorado.

La formación de profesionistas de derecho es genérica en la mayoría de las instituciones de educación superior (IES) mexicanas, por lo que la especialización profesional se logra por medio de la guía pedagógica y la interacción con los colegas más expertos, quienes contribuyen al aprendizaje de los novatos sobre conocimiento práctico, referentes culturales y pautas de comportamientos pertinentes para un ejercicio profesional exitoso. Estos elementos son valiosos porque permiten a los novatos integrarse al gremio jurídico y ser reconocidos por sus colegas como miembros legítimos.

Por ejemplo, para ser visto y tratado como un profesionista competente en un tribunal o en un despacho jurídico de élite, el novato necesita aprender a proyectar la imagen profesional adecuada a las especificidades de ese tipo de organización y función profesional. Por esta razón, es conveniente que la enseñanza formal que llevan a cabo las IES sobre los principios generales de la disciplina jurídica sea complementada con la enseñanza informal propia de los ámbitos laborales.

En otras palabras, cuando los profesionistas novatos ingresan a un ámbito laboral se enfrentan al desafío de obtener información relevante para aprender a ajustarse a la organización y a sus clientes o usuarios, al mismo tiempo que construyen una imagen adecuada. A este proceso, Bourgoin y Harvey (2018) lo denominan tensión de aprendizaje-credibilidad. Para sortear dicha prueba, los novatos necesitan aprender a proyectar la imagen profesional adecuada, es decir, que logren ser vistos y tratados por sus jefes, compañeros y usuarios o clientes con la credibilidad suficiente para desempeñar su trabajo. El propósito de dar una imagen profesional adecuada, más que un fin en sí mismo, es una condición para que el novato logre una interacción, en especial con los colegas, de tal modo que pueda transmitir información, resolver problemas o lograr objetivos a largo plazo (Bourgoin \& Harvey, 2018). 
Nuestro planteamiento es que, durante la mentoría informal, los mentores son modelos de referencia de la imagen profesional adecuada para sus mentorados, quienes aprenden a enviar señales favorables de profesionalismo a sus jefes, colegas y clientes, de tal modo que pueden ser considerados aptos para desempeñar su rol, ganar credibilidad sobre su competencia profesional y recibir un trato acorde con el puesto que ocupan en una organización.

Con base en esta noción, nuestro estudio tiene como objetivo identificar algunos de los saberes que los novatos desarrollan con sus mentores, entre los cuales están los referidos a la construcción de la imagen profesional. Un componente fundamental de esa imagen es el atuendo laboral, ya que, conforme los novatos tienen mayor conciencia de la relevancia de la vestimenta, pueden manejarla para influir en la manera en que otros los ven y obtener mayor poder, influencia y beneficios laborales. Los resultados favorables que suelen ganar los profesionistas que se ajustan a los estereotipos de la imagen profesional pueden confirmar que las organizaciones sí reconocen y recompensan el cuidado que sus empleados tienen en su vestimenta (Peluchette, Karl \& Rust, 2006).

\section{LA IMAGEN PROFESIONAL DESDE LA PERSPECTIVA INTERACCIONISTA}

Goffman (1989) plantea que en los entornos caracterizados por rutinas, reglas y funciones bien definidas, como las organizaciones jurídicas tradicionales, la interacción cara a cara, es decir, "la influencia recíproca de un individuo sobre las acciones de otro cuando se encuentran ambos en presencia física inmediata” (p. 27), se puede analizar a partir de las señales que emiten los actores e identificar los rasgos de la imagen que tratan de proyectar a los demás.

Desde esta perspectiva, reconocemos una fachada social, referida a la información previa, prenociones o estereotipos sobre las características propias de un conjunto de acciones o rutinas que podemos trasladar de una situación a otra; por ejemplo, cuando se piensa en las características de un tribunal, un despacho o una instancia del ministerio público, se tiene una expectativa sobre el desempeño, el lenguaje y la imagen de quienes trabajan ahí aunque nuestra experiencia sea muy limitada en esos ámbitos.

En el nivel individual, la fachada personal está formada por las "insignias del cargo o rango, el vestido, el sexo, la edad y las características raciales, el tamaño y el aspecto, el porte, las pautas de lenguaje, las expresiones faciales, los gestos corporales y otras características semejantes" (Goffman, 1989, p. 35). Por ejemplo, los profesionistas del derecho que trabajan en organizaciones jurídicas tradicionales, como el Poder Judicial, suelen proyectar una imagen conforme a los estereotipos profesionales, como vestir de traje, zapatos formales y portafolios. Al respecto, podemos afirmar que esta decisión no es un asunto menor, pues se ha observado que quienes utilizan su vestimenta para impresionar también suelen experimentar una mejor autopercepción al sentirse confiables, competentes, productivos y amigables (Peluchette, Karl \& Rust, 2006).

Si se piensa en el atuendo laboral como parte de la imagen que el profesionista trata de mostrar en su lugar de trabajo, la presentación personal deja de ser un asunto banal para convertirse en un tema sustancial, que consiste en proyectar profesionalismo y aumentar las posibilidades de ser visto y tratado de acuerdo con el 
rol que pretende desempeñar en la organización. El profesionista puede aumentar su credibilidad y legitimidad si dicha imagen es coherente con las características que los demás actores identifican como propias del puesto; por esta razón, quienes monitorean con mayor conciencia la manera en que son vistos por los demás en el entorno laboral tienen mayores posibilidades de proyectar una imagen conveniente que les permita obtener resultados positivos para su carrera, mientras que las personas con menor conciencia de su imagen pueden manipularla con poco éxito y dejar de recibir algunos beneficios (Turnley \& Bolino, 2001).

La perspectiva de la interacción dramática invita a pensar en la organización como un escenario "que incluye el mobiliario, el decorado, los equipos y otros elementos propios del trasfondo escénico" (Goffman, 1989, p. 34). Aunque cada individuo desarrolla la acción que le corresponde, también necesita los otros actores para llevar a cabo su actuación completa. Desde esta lógica, podemos pensar en los estudiantes de derecho como actores en ciernes que miran tras bambalinas la ejecución de los expertos y, desde esa posición, se familiarizan con el escenario, observan los trucos del maestro, identifican el rol de cada actor y aprenden a presentarse ante los otros individuos, sean clientes, jefes o colegas.

El profesionista aprende poco a poco a proyectar una imagen coherente con la expectativa de los demás actores de los escenarios jurídicos y se va haciendo capaz de mostrar la imagen que pretende. El planteamiento de Goffman (1989) sobre el papel de la imagen profesional es el siguiente:

La sociedad está organizada sobre el principio de que todo individuo que posee ciertas características sociales tiene un derecho moral a esperar que los otros lo valoren y lo traten de un modo apropiado. En conexión con este principio hay un segundo, a saber: que un individuo que implícita o explícitamente pretende tener ciertas características sociales deberá ser en realidad lo que alega ser. En consecuencia, cuando un individuo proyecta una definición de la situación y con ello hace una demanda implícita o explícita de ser una persona de determinado tipo, automáticamente presenta una exigencia moral a los otros, obligándolos a valorarlo y tratarlo de manera que tienen derecho a esperar las personas de su tipo (p. 24).

Con base en estas ideas, es posible pensar en las organizaciones jurídicas como escenarios en los que el novato aprende poco a poco a proyectar la imagen que le ayude a ser concebido y tratado de forma coherente con el rol que pretende desempeñar en la organización; es decir, la imagen es la faceta pública que mostramos, la cual está basada en las valoraciones que nos reflejan los demás (Roberts, 2005).

En el trabajo cotidiano, pensado como la obra en la que el profesionista actúa, hay actores principales, secundarios e incidentales que envían y reciben mensajes, incluso hay una escenografía y ambientación específicas. Ante la cantidad de actores y señales presentes en vida cotidiana, la importancia de enviar señales correctas es mayor. El profesionista que quiera ser visto y tratado acorde con el rol que pretende desempeñar deberá ser capaz de enviar mensajes claros de que posee las cualidades necesarias para hacerlo; es decir, es preciso que remita las señales adecuadas de su profesionalismo.

La imagen profesional es importante para todos los profesionistas; sin embargo, en el gremio jurídico es un elemento trascendental porque la materia de trabajo involucra mantener más relaciones personales que en las ocupaciones que se pueden ejercer de manera independiente; por esta razón, el profesionista jurídico necesita dominar tanto el plano técnico como el relacional para desempeñar su trabajo (De- 
zalay \& Garth, 1997). El atuendo profesional puede ser un elemento influyente para manejar la imagen con resultados positivos tanto en el lugar de trabajo como en la percepción propia (Peluchette, Karl \& Rust, 2006).

En el contexto organizacional, el manejo de la imagen se refiere al conjunto de comportamientos que los actores utilizan para moldear la forma en que son vistos por los demás (Bolino, Long \& Turnley, 2016). Cuando los novatos ingresan a una instancia laboral se enfrentan a lo que Bourgoin y Harvey (2018) han conceptualizado como tensión de aprendizaje-credibilidad, que se trata del desafío de obtener información relevante para aprender a ajustarse a la organización y sus clientes o usuarios al mismo tiempo que construyen una imagen adecuada durante su socialización. Estos autores identificaron que los profesionistas pueden experimentar tres tipos de sospechas de los jefes, clientes y colegas cuando ingresan a una organización: la primera se refiere a su competencia o capacidad profesional; la segunda, a su coherencia sociocultural; y la tercera, al cuestionamiento a su productividad (Bourgoin \& Harvey, 2018).

La construcción de la imagen profesional se ha analizado, por un lado, a partir de los elementos cognitivos, conductuales y de socialización que llevan a cabo los profesionistas para proyectar una imagen favorable en la organización en la que trabajan (Ibarra, 1999; Turnley \& Bolino, 2001; Alvesson, 2001; Bolino, Long \& Turnley, 2016; Bourgoin \& Harvey, 2018). Por otro, hay investigaciones que se han centrado en el análisis de carácter simbólico de las señales verbales y no verbales, en especial por medio de la vestimenta, que son mensajes enviados para mostrar la pertenencia a un grupo o clase social, o bien, como símbolo de profesionalismo (Roberts, 2005; Peluchette, Karl \& Rust, 2006; Peluchette \& Karl, 2007). Nuestra investigación analiza el aprendizaje de los novatos sobre la imagen profesional jurídica, en sintonía con este segundo tipo de estudios sobre el atuendo laboral como señal de profesionalismo.

\section{ESTRATEGIA METODOLÓGICA}

Esta investigación se efectúa desde una perspectiva cualitativa para analizar los aprendizajes de los novatos jurídicos sobre la imagen profesional adecuada para proyectarse como profesionistas competentes. La vestimenta es uno de los temas de especial interés en el análisis. En la delimitación analítica del objeto de estudio consideramos solo a los mentorados; la visión de los mentores sobre el fenómeno rebasa el alcance de este estudio.

Analizamos únicamente experiencias de mentoría informal que, según Van Emmerik (2004), es aquella que se establece sin que la organización intervenga de ninguna manera, y cuyo carácter, propósito y resultados son distintos a los de la mentoría formal, la cual tiene una planeación, estructura y recursos materiales y humanos asignados (Ehrich, Hansford \& Tennent, 2004). En algunos casos, los entrevistados tuvieron una relación de mentoría con un familiar o profesor y, en otras experiencias, ese proceso se llevó a cabo con un experto durante el servicio social o las prácticas profesionales, que son un requisito de las IES.

Una diferencia significativa entre dichas actividades y la mentoría informal es que en esta hubo un compromiso voluntario de mentor y mentorado para invertir tiempo y esfuerzo al proceso de enseñanza-aprendizaje del arte profesional. Aunque todos 
los egresados tuvieron una experiencia como practicantes en alguna instancia laboral, solo algunos establecen una relación personal de mentoría informal, las cuales quedaron sin reconocimiento o certificación de las IES o las instancias laborales.

La información empírica se recolectó mediante entrevistas en profundidad con 40 egresados de la carrera de Derecho de tres IES, de los cuales 21 tuvieron un mentor informal temporal o permanente. Los temas de las entrevistas fueron: datos sociodemográficos, trayectoria académica, características de la formación universitaria, experiencias laborales no remuneradas como servicio social, prácticas profesionales o pasantías, inserción al primer empleo y al actual, características de la profesión jurídica, prestigio e imagen profesional.

En la información recolectada sobre las primeras experiencias en el ámbito laboral surgió el tema de la mentoría informal como una experiencia frecuente entre los egresados y cuya relevancia fue confirmada tanto por quienes tuvieron mentores informales como quienes carecieron de ellos, lo cual revela que, incluso, quienes fueron autodidactas reconocieron los beneficios de esa vivencia.

Los participantes proceden de tres generaciones, es decir, egresaron más o menos en la misma época, con una diferencia de uno, dos o tres años. Todos cursaron la carrera de Derecho genérica, sin ninguna especialidad. Algunos entrevistados trabajan en el sector público (gobierno o Poder Judicial) y otros en el ámbito privado (notaría, empresa o despacho jurídico). Las funciones profesionales que desempeñan son la abogacía, la judicatura, la fiscalía y la notaría. Todos fueron becarios o practicantes sin remuneración económica al menos un año y han ejercido en un empleo formal entre uno y cuatro años; estos últimos son los casos de quienes trabajaban y estudiaban la licenciatura de manera simultánea.

El trabajo empírico se llevó a cabo en tres IES distintas en perfil académico y sociocultural ubicadas en el Estado de México. Las diferencias en la trayectoria de sus profesores, planes de estudio, equipamiento, infraestructura, servicios para los estudiantes, así como los recursos simbólicos, como el prestigio y el reconocimiento social, configuran una experiencia formativa distintiva para cada comunidad estudiantil. La selección de cada institución se basó en el propósito de que cada una fuera representativa de los establecimientos de su tipo, de tal forma que pudieran considerarse una muestra intencionada, teórica y significativa por sus características intrínsecas (Merriam, 1998).

De los entrevistados, trece estudiaron en la Universidad Autónoma del Estado de México (UAEMex), que es pionera en la formación de profesionistas del derecho en la entidad mexiquense, por lo que es un referente para estudiar el fenómeno planteado con base en el supuesto de que sus profesores tienen una amplia trayectoria profesional y pueden ser mentores con experiencia.

Del sector privado, participaron trece profesionistas de la Universidad de Ixtlahuaca (UdIX), cuyas colegiaturas están entre las más bajas del mercado universitario regional; ofrece licenciatura y distintos programas de posgrado en derecho; inició sus labores en 1993 y goza de prestigio local. Tiene una matrícula de licenciatura de aproximadamente 7,500 estudiantes, cifra mayor que la de algunas instituciones públicas y privadas estatales. Gran parte de sus profesores y directivos son egresados de la carrera de Derecho de la UAEMex. 
Catorce entrevistados más proceden del Instituto Tecnológico de Estudios Superiores de Monterrey, campus Toluca (ITESM). Es una de las IES privadas pioneras en el mercado universitario y sus colegiaturas se encuentran entre las más altas de la región. Aunque la carrera de Derecho se ofrece desde 2005 en este campus, esta sede goza de amplio prestigio por pertenecer a una red nacional consolidada. Uno de los supuestos es que en esta institución gran parte de los profesores tiene experiencia y renombre profesional, lo que permitiría brindar buenas prácticas de mentoría.

\section{Discusión}

\section{La mentoría: estrategia pedagógica poderosa}

La socialización profesional es el proceso mediante el cual los individuos son influenciados o moldeados para asimilar y reflejar las dimensiones de valor de una profesión (Barretti, 2004). Un cambio actitudinal relevante que se ha identificado como producto de la socialización es que los estudiantes suelen abandonar de forma progresiva los estereotipos y las imágenes idealizadas sobre su profesión, y aprenden las implicaciones de la práctica profesional cotidiana (Mayer-Sommer \& Loeb, 1981). En otras palabras, abandonan las tierras altas de su disciplina -la perspectiva académica de la universidad- para sumergirse en los terrenos pantanosos -la práctica profesional- donde se requieren conocimientos y habilidades desarrollados mediante la experiencia empírica (Schön, 1998).

Una de las figuras más importantes en la socialización profesional han sido los mentores, quienes han tenido un papel importante en la enseñanza, promoción y desarrollo de habilidades y talentos de las generaciones más jóvenes (Ehrich, Hansford \& Tennent, 2004). En un sentido amplio, un mentor es alguien que forja "una relación profesional y personal más cercana con un subordinado o par, que utiliza sus conocimientos y habilidades para apoyar la carrera de su discípulo, así como su poder de persuasión para animarlo a seguir una trayectoria profesional similar" (Camp, 2006, p. 40). El mentor es una persona influyente por su avanzado conocimiento y experiencia, lo que permite proveer de apoyo a su aprendiz (Van Emmerik, 2004).

En general, esta experiencia de enseñanza-aprendizaje se concentra en tres objetivos: desarrollar habilidades técnicas, ejecutar tareas de administración y gestión, y reforzar las normas y los valores organizacionales (Swap et al., 2001). En este último punto cabe señalar que un mentor brinda consejo e información sobre la cultura y los protocolos organizacionales para que sus mentorados puedan cubrir las expectativas con prontitud. El mentor que puede realizar esas tareas tiene el estatus, la experiencia e influencia suficientes dentro de la organización (Kay, Hagan \& Parker, 2009).

La mentoría se ha asociado a la satisfacción laboral tanto por los beneficios extrínsecos como por los intrínsecos (Ehrich, Hansford \& Tennent, 2004; Camp, 2006; Swap et al., 2001; Van Emmerik, 2004). Para los mentorados, la mentoría brinda la oportunidad de fomentar habilidades, conocimientos y mejorar su desempeño. Para los mentores, promueve el desarrollo profesional y personal. A ambos grupos les ayuda a perfeccionar sus habilidades, acceder a nuevas ideas y promover el desarrollo personal (Ehrich, Hansford \& Tennent, 2004). 
Sin embargo, la mentoría informal también es una experiencia que solo algunos novatos pueden experimentar, porque el acceso a un mentor supone contar con una persona dispuesta a establecer un compromiso personal con el novato para brindarle tiempo y recursos que contribuyan a perfeccionar poco a poco su competencia. En este sentido, los entrevistados comentaron:

Conozco compañeros a los que no los dejaban ni hacer una promoción y no tenían ni la oportunidad de agarrar la computadora y fallar. Si yo fallaba, el licenciado no se molestaba, al contrario, me decía "corrige aquí". Había compañeros que, si no lo hacían bien, los regañaban. Me ha tocado escuchar muchas experiencias así. Yo, la verdad, corrí con suerte (Alma, UdIX).

A menos que tengas un padrino muy bueno que llegue, te agarre de la mano y te diga "¿sabes qué? vas a estar aquí, tú y tú van a estar con él y le enseñan todo", tienes que buscar tus oportunidades, tocar puertas y alguna se tiene que abrir. Hay personas que sí corren con la suerte de tenerlo (Rodrigo, ITESM).

Solo una parte de los novatos del derecho tienen la oportunidad de formarse con un mentor dispuesto a enseñarles y brindarles el apoyo pedagógico y emocional necesario para integrarse al gremio paulatinamente; la mentoría es una relación demandante, compleja y dinámica que requiere tiempo, interés y compromiso de mentores y aprendices (Ehrich, Hansford \& Tennent, 2004).

Sumado a lo anterior, se ha observado que la posibilidad de que las mujeres establezcan una relación de mentoría es menor debido a que el derecho, como otras profesiones dominadas por hombres, ejercidas en su mayoría por estos e influidas por estereotipos masculinos (Ramaswami et al., 2010), es una de las carreras en las que las mujeres necesitan vencer más obstáculos ideológicos y culturales para mostrar su profesionalismo; por ello, se encuentran con menos colegas dispuestos a asumir un compromiso de mentoría. Aquellas que pretenden ser exitosas en este tipo de profesiones deben construir relaciones de mentoría con colegas varones poderosos, en puestos de liderazgo o que les brinden su apoyo (McManus, 2005; Kay, Hagan \& Parker, 2009; Ramaswami et al., 2010).

En perspectiva histórica, desde los inicios de la profesión jurídica mexiquense, el trabajo cotidiano de un novato con un experto ha sido una estrategia pedagógica común. En 1826, el Instituto Literario de Toluca (ahora UAEMex) establecía que, para obtener el título de profesionista del derecho, era preciso "haber estudiado Jurisprudencia en alguno de los Colegios de la República, haber practicado por tres años en estudio de abogado conocido y haber sido examinado y aprobado por el Tribunal Superior de Justicia" (Peñaloza, 1997, p. 5). La preparación del novato consistía en desarrollar a la par el conocimiento teórico y el práctico y, para ser acreedor al título o cédula correspondiente, debía comprobar haber tenido un periodo de aprendizaje al lado de un colega experto.

De acuerdo con la Ley Orgánica de 1851, la formación profesional comprendía cuatro años de teoría y dos de práctica, durante los cuales los estudiantes asistían a una academia de perfil teórico y práctico, que determinaba como obligatoria la asistencia a un juzgado para desempeñarse como practicante. Al respecto, indicaba que, "para obtener el título de abogado, además de acreditar los estudios correspondientes, era requisito presentar examen previo en el instituto y examen recepcional en el Tribunal Superior de Justicia" (Peñaloza, 1997, p. 16). 
Asimismo, la Ley de Educación Pública decretó, en 1926, que los estudiantes que cursaran del "segundo al cuarto año de la carrera debían hacer su práctica en oficinas judiciales de la ciudad de Toluca, bajo vigilancia del Procurador de Justicia del Estado, mientras que, en el quinto año, último de la carrera, debían cursarlo en el bufete de un abogado reconocido" (Peñaloza, 1997, p. 21). En Estados Unidos ocurría algo semejante en la misma época, como señala Collins (1989):

El principal método de enseñanza fue el aprendizaje en un bufete de abogado, durante el cual el estudiante prestaba pequeños servicios como preparar papeles y copiar documentos legales (antes del invento de la máquina de escribir, a final del siglo). En su tiempo libre podía leer cuanto estaba disponible sobre leyes, historia y libros en general. En los bufetes de los abogados destacados, los estudiantes tenían a menudo que pagar honorarios por su aprendizaje (p. 169).

A diferencia de lo que ocurría en los inicios de la profesión, hoy es usual que en las universidades los profesores durante las clases se concentren en revisar "el contenido de una denuncia, de los elementos de un contrato, o los diferentes tipos de entidades legales que existen, más que enfocarse en el desarrollo de mayores habilidades prácticas" (Asociación de la Barra de los Estados Unidos, 2012a, p. 30). Las experiencias didácticas con las cuales los estudiantes pueden desarrollar conocimiento práctico o habilidades relacionales quedan limitadas al servicio social o a las prácticas profesionales en su mayoría.

Sin embargo, también hay casos en los que los novatos tienen oportunidad de aprender de manera informal como lo hacen quienes disponen de un mentor. Una muestra de la iniciativa de los estudiantes para aprender fuera de la IES es que hace casi una década la mitad de quienes estudiaban derecho trabajan como pasantes bajo la supervisión de un abogado con cédula profesional y "algunos estudiantes incluso comienzan a ofrecer asistencia jurídica antes de titularse, contrariamente a lo que indica la ley" (Asociación de la Barra de los Estados Unidos, 2012b, p. 33).

En el caso de los egresados entrevistados para esta investigación, una muestra de la prevalencia de dicho fenómeno es que, de 40 profesionistas, 21 tuvieron un mentor informal; para algunos fue un familiar, para otros un profesor, o bien, el jefe directo durante las prácticas profesionales o el servicio social. Aunque todos los egresados tuvieron que cumplir este requisito, algunos lo hicieron como un trámite poco significativo y otros tuvieron la oportunidad de establecer una relación de mentoría, la cual se efectuó sin ninguna intervención institucional; fue más bien un acuerdo personal.

Un beneficio de la mentoría es que cuando un profesionista imita el comportamiento de su mentor puede aumentar las posibilidades de éxito en su carrera; por ejemplo, en relación con su apariencia física, si proyecta una imagen coherente con la manera en que se espera que luzca un profesionista: disciplinado, limpio, propio, confiable, predecible o comunicativo, puede llamar la atención de sus jefes de manera positiva (Alvesson, 2001).

Un dato interesante es que, de los doce egresados cuyo jefe les enseñó a trabajar durante el servicio social o las prácticas profesionales, tres fueron contratados posteriormente por este, mientras que, en otros casos, el jefe los recomendó con otro empleador o hicieron algún contacto profesional gracias a él. Asimismo, destaca que la función profesional en la que la mentoría suele ser más utilizada es la abogacía, aunque también es frecuente en algunas instancias gubernamentales. 
Con relación a la enseñanza del mentor en asuntos especializados de tipo técnico, una parte crucial del proceso consiste en preparar de manera gradual al novato para realizar las tareas competentes. El mentor toma decisiones pedagógicas para conducir al novato en las tareas más sencillas y constantes a las más complejas y variables, controlar el margen de error de sus actividades y ejemplificar el modo en que se llevan a cabo los procedimientos. Los entrevistados comentaron al respecto:

Llegué y empecé como auxiliar del titular para foguearme con lo que era realmente el oficio. Después que terminé mis prácticas me ofreció la oportunidad de litigar. Comenzó a darme más responsabilidades, aunque no estuviera siquiera con la carrera terminada, empezaba a soltarme un poquito, a darme confianza, porque al ir con alguien más preparado y que lleva años en eso una se siente bien. Cuando empieza una se espanta " $¿ y$ si lo hago mal?, ¿qué tal si me regaña o se me olvidó hacer esto?". Fui muy cobijada por esa persona, tengo que reconocerlo, estoy muy agradecida (Diana, UdIX).

En el despacho, mi jefe me hacía preguntas y yo respondía "no sé". Entonces replicaba “¿cómo no sé?" y se ponía con su pintarrón y me decía "el derecho civil se divide así y así" era como mi maestro, lo que no entendía, me lo decía. Para hacer las demandas yo sabía más o menos cómo, pero tiene puntos clave para cada procedimiento, hay que fundamentar cada cosa que se pide y él me enseñó "aquí está el código, lo puedes checar así". Si me tenía que trasladar a los juzgados, en Google me ponía el planito y me decía “¿sabes qué? vas a tomar este camión”. Me ayudó mucho, me explicaba muy bien, me apoyaba (Artemisa, UdIX).

El servicio social lo realicé en la Procuraduría General de Justicia. Era muy interesante porque con la agente del ministerio público que estuve asignada no era lo tradicional, lo que siempre se piensa del servicio social, que eres el "ve a sacar copias". No, con la titular que estuve fue excelente, me ayudó desde el primer momento, me fue explicando cómo se llevaban a cabo todas las comparecencias y demás. Me fue involucrando y eso fue bueno (Verónica, UdIX).

Estos testimonios destacan la función pedagógica de los mentores, en la que observamos una combinación favorable de un profesionista dispuesto a enseñar y un ambiente organizacional favorable. Por otra parte, el apoyo emocional que un mentor puede brindar a su mentorado es un elemento valioso, pues el experto sirve como guía para aprender a regular la convivencia con los compañeros y resolver conflictos (Kay, Hagan \& Parker, 2009). Asimismo, el mentor muestra las pautas de comportamiento y los valores profesionales importantes para la organización; por ejemplo, cómo ser un buen compañero de trabajo (Swap et al., 2001). Otro beneficio es sobre la autopercepción del mentorado, ya que, al fortalecer la seguridad y confianza en sí mismo, puede mejorar su desempeño profesional. Sobre este tema, los entrevistados opinaron:

Ella ha sido mi guía. La verdad, le agradezco muchas cosas que por ella pude lograr. Una tiene muchas dudas, bueno, en mi caso eran cosas tan tontas y no las sabía. Me daba pena y decía "¡ay! mejor no digo nada". Ella me hizo sacar ese miedo, me decía "ipregunta, aunque sea lo más tonto, pregunta! todo lo que no sepas ipregunta!". Ella me brindó mucha seguridad y confianza en mí misma para salir adelante (Ruth, UAEMex).

Al principio me decía "estas son las carpetas, lee el código, vas a ir viendo por qué esta carpeta se va al archivo y por qué esta carpeta es reserva". Eso fue los primeros días; después, empezamos a ver cómo se tomaba una comparecencia. Al principio me decía "nada más fíjate" ya después me decía "toma la comparecencia". En el escritorio, me ponía de un lado y ella se ponía del otro y empezaba a tomar las comparecencias, me decía "estás 
mal, replantea la pregunta de esta manera". 0 así la dejábamos y ya después me decía "tienes que replantearla así" (Wendy, UdIX).

Estuve en un despacho para darme cuenta de cómo se trabajaba, cómo llegar a un juzgado, solicitar un expediente, ver cuáles eran los acuerdos, temas así. Mi tío me decía "haz esto", entonces, una va empezando a aprender. Él me daba seguridad y me decía "vas a llegar y vas a decir esto y esto". Creo que también es un plus que alguien te dé seguridad, porque como abogadas siempre debemos mostrar seguridad (Verónica, UdIX).

Le ayudaba a la secretaria de proyectos a proyectar sentencias. Me ponía a estudiar los expedientes y emitía mi opinión. Redactaba la proyección de sentencias. Más o menos, en dos meses ya hacía las proyecciones de sentencia y ella la revisaba, me decía "estás bien" o "no estás bien, corrige, modifica". Me sirvió mucho (Eric, UdIX).

En los testimonios observamos cómo los egresados fueron construyendo una imagen propia sobre su capacidad y competencia profesional en la medida en que fueron tomando como propias las atribuciones que hicieron sus mentores, las cuales son influyentes porque proceden de un referente profesional importante que puede representar un modelo para el novato cuando este revisa sus propias fortalezas y cualidades, y cuando reflexiona sobre las características de la mejor versión que puede proyectar de sí mismo (Roberts et al., 2005). Cuando el novato se identifica con el mentor de manera estrecha y advierte que comparte características profesionales con él, puede utilizar esos rasgos que ha desplegado en momentos favorables para conformar su propia imagen profesional.

\section{Del médico la bata y del abogado la corbata: la imagen profesional}

En la mayor parte de las IES, la imagen profesional, y en especial la vestimenta, se considera un asunto complementario o secundario en comparación con la importancia que se atribuye a desarrollar otros conocimientos o habilidades. Sin embargo, en los ámbitos laborales jurídicos el atuendo influye en la imagen profesional que se pretende proyectar, pues las señales no verbales también modelan las percepciones de los demás sobre la propia competencia, carácter y capacidad para cumplir con los estándares culturales de lo que se considera un comportamiento profesional (Roberts, 2005).

La imagen profesional es el conjunto de percepciones que los actores clave, como jefes, subordinados y colegas, tienen sobre la competencia y el carácter de un profesionista (Roberts, 2005). Al respecto, los mentores influyen en las ideas que el novato va atribuyéndose sobre su capacidad profesional; por ejemplo, cuando los mentores reconocen las fortalezas del mentorado, le ayudan a construir una imagen favorable de sí mismo, la cual puede proyectar en el ámbito laboral. Al respecto, los entrevistados refirieron lo siguiente:

No es fácil litigar, uno piensa que sale de la universidad y va a saber cómo empezar algún juicio, pero no. El simple hecho de llegar a checar un acuerdo al juzgado, no sabes ni cómo, todo eso lo aprendes afuera, en la práctica. Hubo una persona donde hice mis prácticas que me ponía casos y me decía "aquí está la causa, quiero que la estudies, que compares". Me decía "eres muy buena, te percatas de muchos detalles". Era muy lindo, paciente, nunca se desesperó conmigo, aunque no sabía nada, aprendí con él (Betania, UdIX). 
Yo hacía promociones, lo acompañaba a diligencias, presidía las audiencias y me presentaba con todos como "la licenciada", yo era estudiante, pero siempre era "la licenciada". Me dejaba a cargo para que atendiera a la gente, me dejaba manejar el despacho y las cosas las hacía como él acostumbraba. Todo me lo revisaba y siempre tuve su apoyo (Alma, UdIX).

El maestro con el que trabajé desde tercer semestre empezó a confiar en mí para los asuntos. Me dijo "confío en ti porque sé que tienes la capacidad". Aunque había cosas que obviamente no sabía, pero él me vio potencial y se lo agradezco, siempre le he agradecido la confianza que me tuvo (Marcos, ITESM).

Estos testimonios hacen evidente la relevancia que adquiere la evaluación del mentor sobre el desempeño del novato, pues la retroalimentación cotidiana de las personas que este toma como modelos de referencia puede tener efectos perdurables en las autoatribuciones que hace sobre su capacidad profesional. Las valoraciones que recibe un profesionista sobre su adecuada capacidad técnica y habilidad social para cumplir con los parámetros de la cultura organizacional o la profesión pueden influir en su éxito laboral (Roberts, 2005).

La imagen profesional adecuada se aprende de manera gradual; de acuerdo con Ibarra (1999), cuando el profesionista se encuentra en el proceso, la construcción de su identidad e imagen profesional prueba con distintas imágenes provisionales de sí mismo antes de asumir por completo aquella que quiere proyectar. Durante la adaptación hacia una imagen definitiva, el profesionista suele realizar tres tareas esenciales: la primera consiste en advertir las identidades potenciales, representadas por quienes elige como sus modelos a seguir; la segunda se basa en experimentar con algunas versiones provisionales de sí mismo, por ejemplo, mediante la imitación de los modelos electos; y la tercera se refiere a evaluar los resultados obtenidos al probar dichas imágenes provisionales, los cuales valora según la retroalimentación externa recibida (Ibarra, 1999).

El proceso de construcción de la imagen es un asunto complejo en el cual el profesionista evalúa y modela las percepciones sobre su propia competencia y carácter (Roberts, 2005). Si envía señales equivocadas, corre el riesgo de generar el efecto opuesto al deseado, de tal forma que si busca ser visto como competente puede proyectar una imagen de presuntuoso o si desea que lo vean como una persona simpática también puede ser percibido como adulador (Bolino, Long \& Turnley, 2016; Turnley \& Bolino, 2001).

En su ejercicio laboral, el profesionista interactúa con personas diversas a las que necesita mostrar que es capaz de desempeñar el rol que ostenta. Ganar credibilidad es un asunto fundamental para que sus jefes, clientes y colegas reconozcan su pericia profesional; si la vestimenta es un elemento esencial de la imagen profesional, entonces los novatos han de ser conscientes de ello. Al respecto, algunos entrevistados recordaron algunas enseñanzas que recibieron en la escuela o de un colega más experto:

Cada profesión se caracteriza por la manera en la que viste o por la manera en que hace las cosas. Efectivamente, a los abogados siempre nos han caracterizado por ser personas trajeadas, muy formales. De hecho, aquí en la institución a partir del tercer semestre nos imponían casi casi la cuestión de que "tienes que venir formal, muy bien trajeado, muy bien peinadito, dirigirte de manera correcta" (Diana, UdIX). 
La persona con la que trabajo me dijo "tienes que vestir de acuerdo con lo que eres". Al principio, como niño chiquito pataleé y me quejé amargamente, pero, en realidad, las personas llegan y te hablan de otra manera si vas vestido de acuerdo con lo que eres, te dicen "oiga, licenciado". Que llegues bañado, de traje, con corbata, con un aspecto favorable es porque te estás vendiendo, aunque suene mal, es una transacción. Que llegues rasurado y bien peinado es para impresionar a las personas que te están contratando (Isaías, ITESM).

Durante la formación universitaria, los novatos recibieron mensajes claros sobre el valor de la vestimenta en el trabajo, lo que refleja la conciencia de su relevancia para la imagen profesional. Al respecto, observamos que el atuendo laboral es valioso, por una parte, para que el profesionista muestre su pertenencia a la profesión jurídica y, por otro, para reforzar la imagen gremial. De manera especial, para el novato podría ser más benéfico vestir conforme a los estándares culturales establecidos para su profesión que hacerlo sin tenerlos en cuenta, pues, en general, las personas desean ser percibidas de acuerdo con los estándares culturales definidos sobre cómo se ve un profesional competente (Roberts, 2005). Los entrevistados comentaron lo siguiente:

Así como del médico es la bata, del abogado es la corbata. Es súper importante, si llegas como abogado a una entrevista de trabajo con jeans, botas, camisa de cuadros, no te toman en serio, ni en el litigio. ¿A quién se le acerca una persona cuando tiene un problema?, ¿al abogado que tiene su pantaloncito de mezclilla y una camisita o al que está junto? Quizá no sabe más que el otro, pero tiene esa presencia, con traje, corbata, bien vestido. Dices "este cuate, por lo menos, se ve abogado", la imagen arrasa (Lucas, UdIX).

La gente dice "sí parece abogado" o "no parece abogado". Es importante que si tuvieras que entrar a un juzgado te vean con toda la personalidad que debe tener un abogado. Para generar confianza necesitas parecer lo que eres y si no pareces abogado la gente no se siente con la tranquilidad de saber que vas a poder desempeñarte como tal. El aspecto físico en el desempeño de mi profesión tiene como un cincuenta por ciento de importancia (Betania, UdIX).

Difícilmente se te van a abrir las puertas si vas creando una imagen que no va acorde a los lugares donde te estás presentando. Así funciona con las personas que están del otro lado del buró, como te ven, te tratan. Muchas ocasiones piensan que lo más importante es lo de adentro, pero también dicen que "de la vista nace el amor". Empezando por vestir como abogado, comportarte como abogado y vivir como abogado, empezarás a ser abogado. Si no, créeme, el mismo gremio te excluye (Juan, UAEMex).

Cuando uno acude al médico se fija en que dé una buena apariencia. Si uno encuentra la bata sucia lo primero que va a pensar es "¿esta persona me va a atender?". Algo similar sucede cuando acuden a un despacho, lo primero que evalúan es la presentación ¿no? Recuerdo a un maestro de la facultad que siempre andaba de mezclilla y botas negras de casquillo. Lo primero que uno se preguntaba era “ ¿este maestro va a dar clases?", uno se daba cuenta que ese maestro no era del gremio (Mateo, UAEMex).

Algunos testimonios ejemplifican cómo a través de la vestimenta es posible proyectar una imagen que señale la capacidad del profesionista para desempeñar su rol:

La imagen de un abogado da seguridad, confianza, o sea, da pauta para decir "de entrada creo que es buen abogado o creo que es bueno en lo que hace". No necesitas tener el traje más caro, la corbata más cara, la camisa más cara o el reloj más caro. Creo que la pulcritud es lo que hace al abogado, no tanto las marcas o el costo de lo que trae, pero obviamente, mucha gente toma piensa "si no tiene dinero para vestir bien, no creo que tenga muchos clientes y no creo que le vaya tan bien" (Marcos, ITESM). 
Nunca se me olvida que mi abuela estaba llevando un caso y estaba buscando un abogado. Entrevistó a un abogado y a un docente, al abogado no lo contrató porque dijo "pobrecito, mira cómo va vestido y en su carrito todo chafa". En cambio, se fue con otro abogado que, aunque le cobraba más y todo, bueno, también se veía más capaz. Se fue mucho por la imagen, las oficinas, el traje, la imagen corporativa que daba (Belén, ITESM).

Aparte de la seguridad que debe proyectar el licenciado en Derecho, también la imagen cuenta mucho. Si usted pone a una persona con un abogado que viene de mezclilla y tenis y otro que viene de traje súper pulcro y con los zapatos boleaditos, obviamente se va a ir con la persona que viene mejor vestida porque le da la seguridad de pensar "él es bueno" (María, UAEMex).

En estos ejemplos también advertimos que los entrevistados asocian la capacidad profesional con el éxito económico. Una posible interpretación de estas opiniones es que si el abogado viste con ropa informal o de bajo costo significa que tiene poco dinero para invertir en su vestimenta y eso se debe a que lleva pocos casos, lo cual sería de esperar de un profesionista poco competente.

El valor de la imagen también puede cambiar según el objetivo del profesionista; por ejemplo, puede ser más importante en momentos decisivos, como cuando se trata de conseguir un trabajo o lograr una mejor evaluación del desempeño (Bolino, Long \& Turnley, 2016). Asimismo, la relevancia del atuendo es variable según el tipo de organización, pues es probable que, en las más institucionalizadas, como el caso de las empresas que refirió una de las entrevistadas, la presentación sea más apreciada como señal de coherencia con el ámbito laboral. Desde la perspectiva organizacional, la vestimenta de los trabajadores también puede ser una estrategia para establecer o reforzar una cultura laboral favorable (Peluchette \& Karl, 2007). En distintos entornos labores, la vestimenta es un elemento clave de la imagen, aunque su objetivo puede ser distinto, como podemos apreciar en estos testimonios:

La imagen es indispensable en la rama corporativa. No es lo mismo llegar a una junta de conciliación y arbitraje medio arreglada que llegar presentable, siempre formal. $\mathrm{Me}$ lo dijeron en la universidad "de lunes a jueves tienes que vestir formal y los viernes, un poco casual". Cuando entré a trabajar, eso fue una regla (Isabel, UAEMex).

Nosotros estamos con personas indígenas y que nos vean con traje, como se acostumbra en la vestimenta de un abogado, los hace parecer menos a ellos porque vienen con sus vestimentas tradicionales, sus indumentarias. Viene gente del campo y que nosotros seamos un poquito estrictos con ellos, creo que hace que estemos poniendo una barrera (Daniela, UdIX).

En el primer caso, la profesionista hace alusión a la vestimenta estereotipada compuesta por traje, zapatos formales, accesorios discretos y portafolios. Este atuendo puede ser más apreciado y coherente en notarías, corredurías, instituciones gubernamentales, empresas o despachos jurídicos. En contraparte, como lo señala la profesionista del segundo caso, en ámbitos laborales como los referidos a asuntos agrarios, de migrantes pobres o indígenas, la imagen puede simbolizar mayor distancia social entre el profesionista y sus usuarios o clientes. Sin embargo, en los dos testimonios se confirma que la vestimenta es una señal clara y fuerte de la imagen profesional de los profesionistas del derecho.

La vestimenta profesional también puede enviar señales sobre el estatus socioeconómico de los profesionistas; esto, por el costo de la ropa. Aunque otros elementos 
como el acento o la entonación, la marca de los accesorios de trabajo que utiliza, como bolígrafo, portafolio o computadora, o bien, la calidad de sus tarjetas de presentación son señales fuertes del estatus social. Sobre este punto, los egresados indicaron:

Un tiempo estuve litigando en materia laboral, convivía con abogados de diferentes estratos sociales y sin detallar en los conocimientos que tuvieran, la apariencia influía bastante. Podía distinguir muy bien quién era el abogado del patrón y quién del trabajador. Creo que hay mucha consideración sobre la imagen, no juzgan tanto lo que sepas o no (Francisco, ITESM).

De repente llegan a la Procuraduría y digo "¿quién es usted, el denunciante?" Honestamente, por la facha pienso "es el denunciante" y dicen "no, soy el abogado" y me quedo así de “¡ah, o.k.!” ¿no? La gente no te respeta si no vas bien vestido (Rosario, UAEMex).

Hay abogados que discriminan, a mí me ha tocado competir contra abogados corporativos que van siempre con unos trajes carísimos. Los ves y dices "le toco el traje y se lo rayo y ahí se va toda mi quincena o mi anualidad". Ellos se basan en la presentación. Si llegas con tu traje que se mancha de maquillaje cuando saludas a una persona, se te quedan viendo y te dicen "¿qué abogado?, ¿tan bien le pagan que no le alcanza para un traje?". Me ha tocado y se siente feo (Jesús, ITESM).

Estos testimonios muestran cómo la vestimenta revela el estatus social, así como las atribuciones que los propios entrevistados hicieron sobre sus colegas. El primero de ellos señala que, por la vestimenta del profesionista, podía distinguir con qué tipo de clientes trabajaba. Los otros dos testimonios ejemplifican la discriminación entre colegas por el atuendo profesional que portan. El tercer ejemplo ilustra cómo las autoatribuciones basadas en la impresión causada por la apariencia o la ropa utilizada pueden tener un impacto profundo en la percepción que se forma de sí mismo (Peluchette \& Karl, 2007). Este testimonio muestra el impacto emocional del novato por las palabras del colega sobre su atuendo.

\section{CONCLUSIONES}

La imagen profesional es el conjunto de señales que el profesionista necesita proyectar para ser visto y tratado conforme al rol que pretende desempeñar en la organización. El novato debe aprender a mostrar una imagen favorable para fortalecer la credibilidad de los demás en su competencia profesional; esto también se convierte en un recurso para seguir aprendiendo a trabajar en ámbitos jurídicos y disipar las sospechas de sus jefes, colegas y clientes sobre su capacidad para ejercer su puesto. De esa forma, puede ser visto y tratado como un integrante legítimo del gremio y realizar su trabajo con una mejor percepción de sí mismo.

Durante el proceso en el que el novato aprende a proyectar la imagen profesional en una versión definitiva, los mentores informales y otros colegas expertos le sirven como modelos de referencia. Conforme estos expertos le brindan retroalimentación sobre su desempeño, le ayudan a atribuirse características de su propia imagen profesional, la cual puede hacer evidente en los ámbitos laborales. El mentor informal es fundamental como maestro del arte profesional: por una parte, enseña a su mentorado a pensar como abogado; es decir, le muestra cómo utilizar el conocimiento jurídico en instancias y procedimientos especializados; por otra, desarrolla la dimensión 
sociocultural, referida a los elementos de supervivencia social: pautas de comportamiento, habilidades relacionales, así como valores y actitudes profesionales.

En la medida en que el novato recibe valoraciones sobre las características de la imagen profesional que proyecta, puede modelarla para preservar lo que le favorece y eliminar lo que causa un efecto indeseado. Esta retroalimentación contribuye a configurar la imagen profesional que el novato hace de sí mismo. En este contexto, la vestimenta también sirve como un símbolo que le ayuda a sentirse más competente o eficiente cuando viste de modo apropiado (Peluchette \& Karl, 2007).

El atuendo laboral individual contribuye a reforzar la imagen gremial, aunque su valoración depende de la cultura organizacional y el tipo de clientes que se atienden en ella. La relevancia de la vestimenta puede ser variable según el momento de la trayectoria profesional; puede servir como señal poderosa en algunas transiciones, por ejemplo, al buscar una contratación o ascenso.

En nuestro estudio se hicieron evidentes en los testimonios algunos efectos colaterales de la vestimenta laboral: por una parte, constituye una señal fuerte del estatus socioeconómico del profesionista y, por otra, puede ser motivo de discriminación entre los propios colegas, incluso los mismos entrevistados hicieron atribuciones de la capacidad profesional de otros integrantes del gremio basadas en el costo de la vestimenta, al considerar que invertir en el atuendo laboral se puede reflejar en un mayor éxito económico, el cual sería reflejo de una capacidad profesional probada.

\section{REFERENCIAS BIBLIOGRÁFICAS}

Alvesson, M. (2001). Knowledge work: Ambiguity, image and identity. Human Relations, núm. 7, vol. 54, pp. 863-886. doi.org/10.1177/0018726701547004

Asociación de la Barra de los Estados Unidos (2012a). Índice para la reforma de la educación jurídica. Estados Unidos de América.

Asociación de la Barra de los Estados Unidos (2012b). Índice para la reforma de la profesión jurídica. Estados Unidos de América.

Barretti, M. (2004). What do we know about the professional socialization of our students? Journal of Social Work Education, núm. 2, vol. 40, pp. 255-283. doi: 10.1080/10437797.2004.10778493

Bolino, M., Long, D. \& Turnley, W. (2016). Impression management in organizations: Critical questions, answers, and areas for future research. Annual Review of Organizational Psychology and Organizational Behavior, vol. 3, pp. 377-406. doi: 10.1146/annurev-orgpsych-041015-062337

Bourgoin, A. \& Harvey, J. F. (2018). Professional image under threat: Dealing with learning-credibility tension. Human Relations, núm. 12, vol. 71, pp. 1611-1639. doi: 10.1177/0018726718756168

Camp, R. A. (2006). Las élites del poder en México: perfil de una elite de poder para el siglo XXI. Ciudad de México: Siglo XXI Editores.

Collins, R. (1989). La sociedad credencialista: sociología histórica de la educación y de la estratificación. Madrid, España: Ediciones Akal.

Dezalay, Y. \& Garth, B. (1997). Law, lawyers and social capital: Rule of law' versus relational capitalism. Social \& Legal Studies, núm. 1, vol. 6, pp. 109-141. https://doi: 10.1177/096466399700600105 
Ehrich, L. C., Hansford, B. \& Tennent, L. (2004). Formal mentoring programs in education and other professions: A review of the literature. Educational Administration Quarterly, núm. 4, vol. 40, pp. 518-540. https://doi: $10.1177 / 0013161 X 04267118$

Goffman, E. (1989). La presentación de la persona en la vida cotidiana. Buenos Aires: Amorrortu Editores.

Ibarra, H. (1999). Provisional selves: Experimenting with image and identity in professional adaptation. Administrative Science Quarterly, núm. 4, vol. 44, pp. 764-791. https://doi.org/10.2307/2667055

Kay, F. M., Hagan, J. \& Parker, P. (2009). Principals in practice: The importance of mentorship in the early stages of career development. Law \& Policy, núm. 1, vol. 31, pp. 69-110. https://doi.org/10.1111/j.1467-9930.2008.00285.x

Mayer-Sommer, A. P. \& Loeb, S. E. (1981). Fostering more successful professional socialization among accounting students. The Accounting Review, núm. 1, vol. 56, pp. 125-136. Recuperado de https://www.jstor.org/stable/246468

McManus, E. K. (2005). Intimidation and the culture of avoidance: Gender issues and mentoring in law firm practice. Fordham Urban Law Journal, núm. 1, vol. 33, pp. 1-14. Recuperado de https://ir.lawnet.fordham.edu/ulj/vol33/ iss $1 / 7$

Merriam, S. B. (1998). Qualitative research and case study applications in education: Revised and expanded from case study research in education. San Francisco, CA: Jossey-Bass Publishers.

Peluchette, J. V. \& Karl, K. (2007). The impact of workplace attire on employee self-perceptions. Human Resource Development Quarterly, núm. 3, vol. 18, pp. 345-360. https://doi.org/10.1002/hrdq.1208

Peluchette, J. V., Karl, K. \& Rust, K. (2006). Dressing to impress: Beliefs and attitudes regarding workplace attire. Journal of Business and Psychology, núm. 1, vol. 21, pp. 45-63. https://doi.org/10.1007/s10869-005-9022-1

Peñaloza, I. (1997). Facultad de derecho: una larga tradición. Estado de México, México: Cuadernos Universitarios UAEMex.

Ramaswami, A., Dreher, G. F., Bretz, R. \& Wiethoff, C. (2010). The interactive effects of gender and mentoring on career attainment: Making the case for female lawyers. Journal of Career Development, núm. 4, vol. 37, pp. 692-716. https://doi.org/10.1177/0894845309358886

Roberts, L. M. (2005). Changing faces: Professional image construction in diverse organizational settings. Academy of Management Review, núm. 4., vol. 30, pp. 685-711. https://doi.org/10.5465/amr.2005.18378873

Roberts, L. M., Dutton, J. E., Spreitzer, G. M., Heaphy, E. D. \& Quinn, R. E. (2005). Composing the reflected best-self portrait: Building pathways for becoming extraordinary in work organizations. Academy of Management Review, núm. 4, vol. 30, pp. 712-736. https://doi.org/10.5465/amr.2005.18378874

Schön, D. (1998). El profesional reflexivo: cómo piensan los profesionales cuando actúan. Barcelona, España: Paidós.

Swap, W., Leonard, D., Shields, M. \& Abrams, L. (2001). Using mentoring and storytelling to transfer knowledge in the workplace. Journal of Management Information Systems, núm. 1, vol. 18, pp. 95-114. https://doi.org/10.1080/0 7421222.2001 .11045668 
Turnley, W. H. \& Bolino, M. C. (2001). Achieving desired images while avoiding undesired images: Exploring the role of self-monitoring in impression management. Journal of Applied Psychology, núm. 2, vol. 86, pp. 351-360. https:// doi.org/10.1037//0021-9010.86.2.351

Van Emmerik, I. H. (2004). The more you can get the better: Mentoring constellations and intrinsic career success. Career Development International, núm. 6, vol. 9, pp. 578-594. https://doi.org/10.1108/13620430410559160 